\title{
Acute Hydrocephalus as a Complication of Cervical Spine Fracture and Dislocation: A Case Report
}

\author{
Yoon Young Chung ${ }^{1}$, Chang II $\mathrm{Ju}^{2}$, Seok Won $\mathrm{Kim}^{2}$, Dong Min $\mathrm{Kim}^{3}$ \\ Departments of Anatomy ${ }^{1}$, Neurosurgery ${ }^{2}$, Internal Medicine ${ }^{3}$, College of Medicine, Chosun University, Gwangju, Korea
}

Hydrocephalus is a well-known complication of head injury, but an uncommon complication of a spinal lesion. Here, we present a rare case of acute obstructive hydrocephalus secondary to a cervical fracture and dislocation. A 60-year-old female patient was transferred to the emergency department with quadriplegia and respiratory difficulty. Imaging studies showed a cervical fracture and dislocation at the C3-4 level. She required intubation and mechanical ventilation. Twenty-four hours after admission, her mental status had deteriorated and both pupils were dilated. Computed tomography of the brain showed acute hydrocephalus; therefore, extraventricular drainage (EVD) was performed. After the EVD, her mental status recovered and she became alert, but she remained quadriplegic and dependent on the ventilator. Two months after injury, she died because of respiratory failure caused by pneumonia.

Key Words: Hydrocephalus · Cervical · Fracture

\section{INTRODUCTION}

Hydrocephalus is a well-known complication of brain lesions, but it can also be a rare complication of a spinal lesion. It has been described in association with spinal tumors, spinal infections, and congenital anomalies of the cervicomedullary junction ${ }^{4,5,79)}$. However, acute obstructive hydrocephalus caused by cervical fracture and dislocation has been reported extremely rarely. Here, we present a rare case of acute obstructive hydrocephalus following a cervical fracture and dislocation. We also discuss possible pathogenic mechanisms and review relevant literatures.

\section{CASE REPORT}

A 60-year-old female patient was referred to our emergency room (ER) with quadriplegia and respiratory difficulty. Prompt intubation and mechanical ventilation support were required

- Received: February 28, 2014 • Revised: April 21, 2014

- Accepted: April 23, 2014

Corresponding Author: Seok Won Kim, MD

Department of Neurosurgery, School of Medicine, Chosun University, 365

Pilmun-daero, Dong-gu, Gwangju-city 501-717, Korea

Tel: +82-62-220-3126, Fax: +82-62-227-4575

E-mail: ns64902@hanmail.net/chosunns@chosun.ac.kr

@This is an Open Access article distributed under the terms of the Creative

Commons Attribution Non-Commercial License (http://creativecommons.org/ licenses/by-nc/3.0/) which permits unrestricted non-commercial use, distribution, and reproduction in any medium, provided the original work is properly cited. in the ER. On neurological examination, her mental state was alert and cranial nerve functioning was normal, showing no evidence of head injury. However, she showed quadriplegia and anesthesia below the C3 dermatome and her respiration was faint. We also detected decreased anal tone and loss of urinary sense. Computed tomography (CT) of brain revealed no evidence of abnormalities such as hemorrhage or hydrocephalus (Fig. 1). Plain cervical radiography and CT scan of cervical spine revealed a fracture and dislocation at the C3-4 level (Fig. 2). Cervical spine magnetic resonance imaging (MRI) with ventilator support demonstrated severe cord compression with evident signal change at the C3-4 level (Fig. 3). Because of her inability to breathe independently, she was treated conservatively with high-dose methylprednisolone and intravenous fluid. However, 24 hours after the admission, her mental status had deteriorated to stupor, and both her pupils had dilated to $5 \mathrm{~mm}$. Emergent CT of the brain revealed acute hydro-

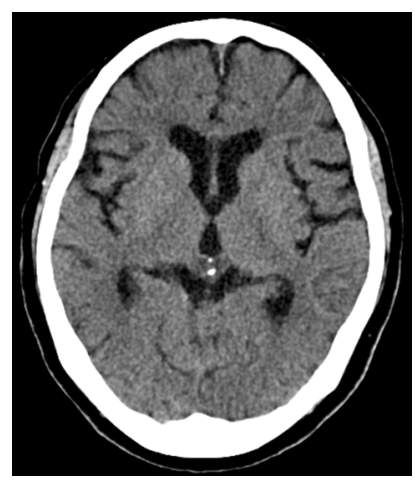

Fig. 1. Initial computed tomography of the brain shows no hemorrhage or ventricular dilatation. 

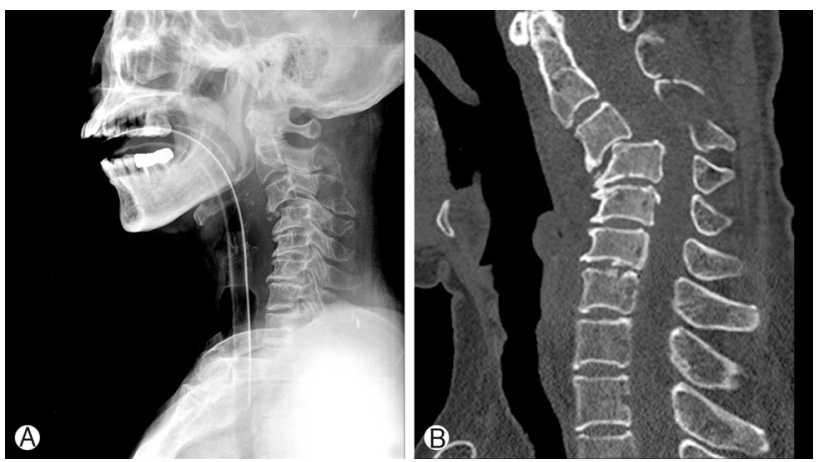

Fig. 2. Plain lateral radiography and computed tomography of the cervical spine reveal fracture and dislocation at the C3-4 level.

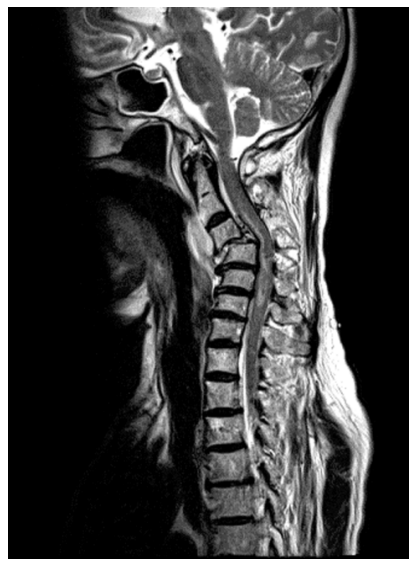

Fig. 3. T2-weighted sagittal magnetic resonance image shows severe cord compression and signal change.

cephalus but no hemorrhage (Fig. 4). To alleviate the symptoms, we performed lumbar cerebrospinal fluid (CSF) drainage. The pressure of lumbar drainage was $18 \mathrm{~cm} \mathrm{H}_{2} \mathrm{O}$. Despite lumbar drainage, her symptoms did not improve. Therefore, emergent extraventricular drainage (EVD) was performed. After the EVD, her mental status improved to drowsiness. However, 4 days after EVD when the drainage catheter was removed, she fell into a deep stupor and the pupillary reflex disappeared. Her family refused further treatment, and she became comatose and expired 2 months after injury because of respiratory failure, in spite of mechanical ventilator support.

\section{DISCUSSION}

Hydrocephalus is a well-known complication of head injury but an uncommon complication of a spinal lesion. Acute hydrocephalus is thought to result from the blockage of CSF flow in the brain. Specifically, blockage of the ventricular system at the outlet foramen or structural blockage of the arachnoid villi generates a pressure gradient that ultimately leads to the enlargement of the ventricles ${ }^{2}$.
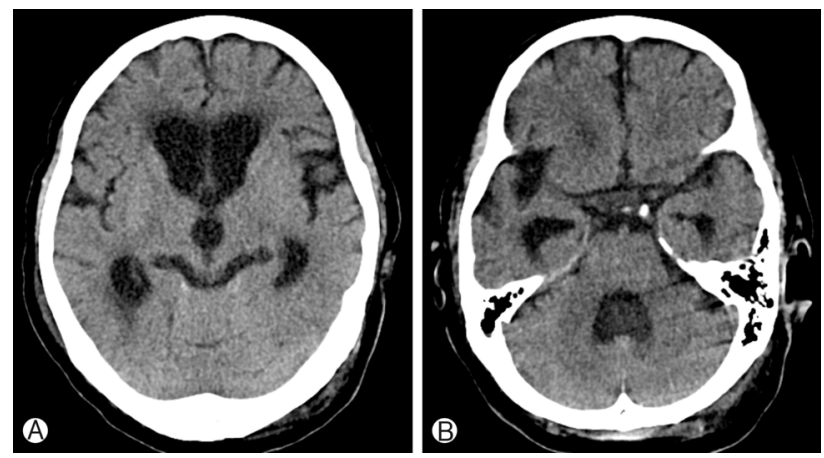

Fig. 4. Brain computed tomography obtained at 24 hours after admission shows marked enlargement of the lateral, third, and fourth ventricles.

On the contrary, hydrocephalus caused by spine pathologies, such as spinal tumors, spinal infections, postcervical myelography, and congenital abnormalities of the cervicomedullary junction, has been reported. In these cases, the pathology was thought to be caused by the disruption of CSF flow, impaired absorption at arachnoid villi due to elevated CSF protein or fibrinogen, tumor infiltration into the cistern, direct compression of the ventricular outlet, or compression of the spinal venous plexus by the tumor itself. However, hydrocephalus after spinal trauma is extremely rare. Hydrocephalus may either be communicating or non-communicating. The non-communicating type is usually the result of the obstruction of CSF flow due to congenital anomalies such as aqueduct stenosis or tumors. The communicating hydrocephalus is usually post-inflammatory in origin and complicated by acute or chronic meningitis. It may follow hemorrhage or trauma when blood is present in the CSF. This may degrade the absorption of CSF at the arachnoid villi ${ }^{3)}$. Hydrocephalus that results from head injury is usually communicating ${ }^{8)}$.

In our patient, however, we believe that the pathogenesis may be related to non-communicating hydrocephalus. The first possible mechanism is the direct compression of the CSF outlet pathways. Menendez et al. ${ }^{6}$ reported a case of hydrocephalus with an occipital condylar fracture fragment pushing into the medulla oblongata. This bone fragment may have caused direct compression and obstruction of CSF outlets, such as the fourth ventricle, foramen of Magendie, or foramen of Luschka.

The second plausible mechanism of hydrocephalus is a spinal cord edema secondary to complete cord injury. Yablon et al. ${ }^{10)}$ suggested that the swelling of the spinal cord, observed after spinal trauma, may extend up to two vertebral segments above and below the injured vertebrae. Challagundla et al. ${ }^{1}$ reported a case of hydrocephalus following fracture dislocation of C5-6 in a patient with ankylosing spondylitis. He postu- 
lated that hydrocephalus resulted from the obstruction of CSF flow at the fourth ventricular outlets due to the ascending edema of the medulla oblongata from the cervical spine. We conjecture that an edema, ascending the spinal cord to brain stem, may have obstructed the CSF flow pathways at the fourth ventricular outlets and raised intracranial pressure in our patient.

\section{CONCLUSION}

Acute hydrocephalus resulting from complete spinal cord injury following cervical fracture and dislocation is an unusual complication. Although rare, it should be considered if the patient's level of consciousness deteriorates after spinal cord injury.

\section{ACKNOWLEDGEMENT}

This study was supported by research funds from Chosun Univerity grant 2014.

\section{REFERENCES}

1. Challagundla SR, Joseph G, Brown J, McLean AN, Fraser MH: Hydrocephalus complicating a cervical spine fracture in a patient with ankylosing spondylitis. Br J Neurosurg 22:700-701,
2008

2. Fuentes S, Metellus P, Adetchessi T, Dufour H, Grisoli F: Idiopathic acute obstructive hydrocephalus. case report. Neurochirurgie 52:47-51, 2006

3. Joseph G, Johnston RA, Fraser MH, McLean AN: Delayed hydrocephalus as an unusual complication of a stab injury to the spine. Spinal Cord 43:56-58, 2005

4. Kim DS, Im SB, Shin WH, Hwang SC, Kim BT, Lee KW, et al.: A case of recurrent shunt malfunction treated with ventriculoureteral shunt after removal of epidermoid tumor. Korean J Spine 4(2):76-80, 2007

5. Kim YD, Kim DH: Lumbar schwannoma associated with hydrocephalus. J Korean Neurosurg Soc 37:228-231, 2005

6. Menendez JA, Baskaya MK, Day MA, Nanda A: Type III occipital condylar fracture presenting with hydrocephalus, vertebral artery injury and vasospasm: case report. Neuroradiology 43: 246-248, 2001

7. Mirone G, Cinalli G, Spennato P, Ruggiero C, Aliberti F: Hydrocephalus and spinal cord tumors: a review. Childs Nerv Syst 27:1741-1749, 2011

8. Nathoo N, Boodhoo H, Nadvi SS, Naidoo SR, Gouws E: Transcranial brainstem stab injuries: a retrospective analysis of 17 patients. Neurosurgery 47:1117-1122, 2000

9. Son S, Lee SG, Park CW, Kim WK: Acute hydrocephalus following cervical spinal cord injury. J Korean Neurosurg Soc 54:145147, 2013

10. Yablon IG, Ordia J, Mortara R, Reed J, Spatz E: Acute ascending myelopathy of the spine. Spine (Phila Pa 1976) 14:1084-1089, 1989 